\title{
Effect of Dysfunctional Attitudes on Orientation of Anger in Major Depressive Disorder
}

\author{
Shaoni Roy Chowdhury*, Prof. Sadhan Das Gupta**
}

\section{ABSTRACT:}

The purpose of this study was to identify the influence of Dysfunctional Attitudes in delineating the orientation of Anger among Major Depression Disorder patients and control population. Dysfunctional Attitude has long been established as a precursor of depressive symptoms. However there is a dearth of studies on the correlates of Dysfunctional Attitude and orientation of Anger. A total of 60 participants (30 Major Depression Disorder, 30 Control) were asked to fill up a self-report paper pencil questionnaire that measured orientation of Anger, Neuroticism and Dysfunctional Attitude. Results indicated higher Anger suppression, Dysfunctional Attitude, and higher neuroticism scores for the clinical group than control group. When Neuroticism was controlled, Dysfunctional Attitude was found to be positively correlated with temperamental and Internalized Anger in the clinical group; however in the control group it remained uncorrelated with the direction of Anger. Stepwise multiple regressions indicated Dysfunctional Attitude to be significant predictor of Internalized Anger in clinical group while Neuroticism was found to be a significant predictor of Internalized Anger for the control group. The present finding suggests the role of Dysfunctional Attitude in defining the orientation of Anger among the Major Depression Disorder group and also elucidates the relationship between Dysfunctional Attitude and Neuroticism with both Internalized and Externalized Anger.

Keywords: Dysfunctional Attitude, Major Depression Disorder, Neuroticism, Internalized Anger, Externalized Anger

\section{INTRODUCTION}

Dysfunctional cognitions and Anger have been recognized to play a fundamental role in the development of depression across time. It has been identified to be one of the cognitive vulnerability factors to the development of emotional disorders (Lomax et al., 2011; Altareb, 2012), and are considered as predisposing risk factors for depressive episodes or indirectly as a factor of vulnerability under the stressful conditions (Lam. D., 1998). Ebrahimi et al., 2012 in their study showed that with an increase of a level in categorized Dysfunctional Attitude Scale 26 (DAS-26) scores the risk of depression increases 4.78 times.

* \& **, Department of Applied Psychology, University of Calcutta, Rashbehari Shiksha Prangan, 92, Acharya Prafulla Chandra Road, Kolkata, India

(C) 2014, S Chowdhury, S Gupta; licensee IJIP. This is an Open Access Research distributed under the terms of the Creative Commons Attribution License (http://creativecommons.org/licenses/by/2.0), which permits unrestricted use, distribution, and reproduction in any Medium, provided the original work is properly cited. 
Dysfunctional Attitude has also been associated with aggression in several studies, one such study carried out on offender samples, found that the frequency of negative, aggression-related thoughts was significantly higher for violent offenders as compared to non-violent offenders (Doucette-Gates, Firestone and Firestone, 1999). A study on driving tendencies by Nesbita, et al (2012) reported of the presence of specific cognitive distortions among the high aggressive drivers.

Previous studies on the role of Anger in depression have yielded mixed findings. Some of the studies have linked violent behavior (Swanson 1990), greater amount of total Anger and Anger expression (Koh et. al., 2002) with depression, while other studies corroborates the concept that Anger aimed towards the self is linked with depression (Becker \& Lesiak, 1977; Wolfersdorf \& Kiefer, 1998; Goldman \& Haaga, 1995; Brody et al, 1999).

Although both the factors Dysfunctional cognition and Anger have frequently been linked with depression, very few studies have explored the relation between Dysfunctional Attitude and orientation of Anger in depressive and normal population. It is important to increase our understanding of this relation, as Anger problems are very much common among Major Depressive Disordered patients and little is known about its association with Dysfunctional Attitude which has been identified as a contributory factor for the development of depressive symptoms. Again, on the basis of the above-mentioned studies we can conclude that there is a definite relationship between Anger and depression in the West; however, in India very few studies have investigated the orientation of Anger in depressive population. As culture seems to influence an individual's way of comprehension and reason, it is crucial to understand this link in an Indian context. Our study addresses these issues and builds on the existing researches by studying the interrelationship of Dysfunctional Attitude, and Anger orientation among normal and MDD population in India.

The main focus of this study was to explore the forms of Anger that were associated with Dysfunctional Attitude as well as to reanalyze the relation of Anger with depression in India.

Three hypotheses were formulated on the basis of previous studies:

- Anger scores would be higher for the clinical group,

- Dysfunctional Attitude would be positively correlated and act as a predictor for Internalized Anger in both the groups.

- Clinical group would have higher Internalized Anger and lower Externalized Anger than the control group.

Along with Dysfunctional Attitude, Neuroticism has long been highly associated with both depression and Anger (Sharpe and Desai, 2001; R. Martin, Watson, and Wan 2000; Rowland, Alison V 2012; Akiskal, Hirschfeld, Yerevanian 1983; Barnett Gotlib, 1988; Widiger Trull, 1992), so the current study has included a measure of neuroticism as a covariate. 


\section{Effect of Dysfunctional Attitudes on Orientation of Anger in Major Depressive Disorder patients}

\section{METHODS}

Sample: The study was conducted with MDD patients and normal Community participants. Both the groups were matched in terms of age, sex, socio economic status and educational background, and language. All the participants belonged to Bengali community and lived in Kolkata, West Bengal. Participants were selected following snowballing method.

The clinical group consisted of 30 patients (13 male and 17 female) suffering from Major Depressive Disorder, with high suicidal ideation aged between 20 years to 40 years $(\mathrm{M}=27.63$; $\mathrm{SD}=5.68)$. The mean age of male patients were 27.85 years $(\mathrm{SD}=5.77)$, and females were 27.47 years $(\mathrm{SD}=5.78) .53 \%$ of the population was married and $47 \%$ were unmarried. Patients were selected from the outpatient department of a psychiatric clinic. Diagnoses for clinical participants were established by two trained psychiatrists. Patients with childhood onset of the illness were excluded from the study. Patients having comorbidity of other anxiety or mood disorders were not included in the study. To counteract the drug effects only patients who were not taking any medications for the illness were included in the study.

The control group consisted of 30 Community participants. From a pool of large number of normal subjects, 30 individuals screened by General Health Questionnaire that matched the clinical group in terms of age, sex, socio economic status, educational background, language were selected from the community. Volunteer participants belonged to heterogeneous background (Graduate students, Post graduate University students, Servicemen, Housewives etc.). Guidelines of inclusions were: Participants should be aged between 20 years to 40 years, they should be from middle class background, and volunteers should be devoid of any mental and physical illness. High school matriculation was the minimum educational criteria. Control subjects having history of hospitalization for any major physical/psychiatric disease were excluded. The Mean age of the participants were 27.71 years $(\mathrm{SD}=5.55), 53 \%$ of the population were female $(M=27.6 ; S D=5.75), 47 \%$ were male $(M=27.81 ; S D=5.41) .53 \%$ of the population was married and $47 \%$ were unmarried. $73 \%$ of the sample had 15years of education and $5 \%$ had 13 years of education and $5 \%$ had 17 years of education.

\section{Measures: Four questionnaires were administered in the present study:}

1. The NEO 5 Factor Inventory (NEO-FFI; Costa \& McCrae 1992): It is a 60-item, 5-point Likert-style instrument that measures each of the Big Five personality factors (Neuroticism, Extraversion, Openness, Agreeability, Conscientiousness). The instrument is a short form, consisting of the psychometrically strongest items from the revised NEO Personality Inventory (NEO PI-R). Internal consistency alphas of .86, .77, .68, and .81 were obtained for the NEOFFI Neuroticism, extraversion, openness, agreeableness and conscientiousness scales respectively, while three month test-retest correlation ranged from .75 to .83 . Validity evidence for the NEO-FFI includes independent self and observer agreement, concurrent predictions of real world behavior and discriminant and convergent correlations with similar instruments. In the present study only the neuroticism subscale consisting of 12 items was used. 
2. State Trait Anger Expression Inventory (Spielberger, 1996): It is a 44-item, 4-point scale that measures the experience and expression of Anger. It measured 5 main components of Anger: State Anger (a 10 item scale measuring intensity of angry feelings at a specific time), Trait Anger consisting of 10 items measuring individual difference in the disposition to experience Anger. Trait Anger has 2 subscales: Angry temperament (measures a general disposition to experience and express Anger without provocation) and Angry Reaction (measures individual difference in the disposition to express Anger when treated unfairly by others), Anger-in (frequency with which Anger feelings are suppressed), Anger-out (frequency of expression of Anger outwards), Anger-control (frequency with which an individual attempts to control the expression of Anger) and a final component Anger-expression (frequency with which Anger is expressed regardless of direction) based on the responses of the former items. The alpha scores of .86 (males) .81 (females) for Ax-In, .75 (males) - .78 (females) for Ax-Out, .81 (males) - .88 (females) for Ax-Control were reported by STAXI professional manual.

3. The Dysfunctional Attitude Scale (Weissman, 1979): It is a self-report paper pencil test consisting of 40 items measuring the relatively stable Dysfunctional believes that are thought to indicate a person's self-evaluation and are associated with depressive symptoms. Participants are required to respond on a 7-point scale (i.e., totally agree, agree very much, agree slightly, neutral, disagree slightly, disagree very much, and totally disagree). The items depicted seven major value systems: Approval, Love, Achievement, Perfectionism, Entitlement, Omnipotence, and Autonomy. Studies have reported good test-retest reliability (correlation of .84 over an 8-week period; Weissman, 1979). Internal consistency reliability was reported to be very good (alpha = .93) (Beevers et al., 2007).

4. General Health Questionnaire: It is a 28 item self-administered, paper pencil, screening device that assesses somatic symptoms, anxiety and insomnia, social Dysfunction and severe depression in the general population. Time taken for completion of the test is 5 minutes. Test Retest reliability has been reported to be high (0.78 - 0.9) (Robinson and Price, 1982). High internal consistency has also been reported (Failde and Ramos, 2000). Validity in comparison with patients' overall clinical assessment is $r=.70$ to .83 . In comparison with clinical ratings for two large group of general medical patients has been found to be $r=.67$ to .76 .

\section{Procedure:}

It was a cross sectional study. Community participants were selected through snowballing method. All participants were asked to respond to three self-rating questionnaires, Dysfunctional Attitude Scale, and State Trait Anger Expression Inventory, Neuroticism subscale of NEO FFI scale. All the measures were individually administered and the purpose of the study was explained in an informed consent form which was collected before the tests were administered. In addition an interview session was done with each patient for the clinical group, to eliminate other co-morbid symptoms. 


\section{RESULTS}

\section{Statistics:}

Before conducting data analysis, a normality test was done on the data to ensure that it met all the necessary requisites for conducting parametric tests like T tests, Pearson product moment etc. Normality tests revealed no significant deviations from normality.

$\mathrm{T}$ test was conducted to assess the mean score differences between the two groups across the variables. A partial correlation was done to assess the nature of association among the variables in each group. Finally a stepwise multiple regressions were done for each group to examine the extent to which the variables Dysfunctional Attitude and Neuroticism contributed to the variable of Internalized Anger.

\section{Group Comparison:}

The clinical group was found to have higher Anger suppression and expression mean scores along with trait Anger scores, than control group. Neuroticism and DA scores were also found to be higher in case of the clinical group. Anger control scores and outward Anger scores were found to be lower in the clinical group.

$\mathrm{T}$ tests revealed a significant higher score in all the variables in the clinical group except Anger control and Externalized Anger. A significant higher Neuroticism score were observed in Clinical group. DA scores were found to be significantly lower in case of normal group. The mean score comparison of the two groups are provided in table I. 
Effect of Dysfunctional Attitudes on Orientation of Anger in Major Depressive Disorder patients

Table I, Comparison of scores of the two groups on STAXI, DA and Neuroticism subscale

\begin{tabular}{|c|c|c|c|c|c|c|}
\hline Variables & Groups & $\mathbf{N}$ & Mean & SD & $T$ & Sig \\
\hline Trait & $\begin{array}{l}\text { Normal } \\
\text { MDD }\end{array}$ & $\begin{array}{l}30 \\
30\end{array}$ & $\begin{array}{l}18.100 \\
27.000\end{array}$ & $\begin{array}{l}4.751 \\
6.978\end{array}$ & -5.774 & .000 \\
\hline $\mathrm{T}$ & $\begin{array}{l}\text { Normal } \\
\text { MDD }\end{array}$ & $\begin{array}{l}30 \\
30\end{array}$ & $\begin{array}{l}6.267 \\
10.200\end{array}$ & $\begin{array}{l}2.212 \\
4.318\end{array}$ & -4.440 & .000 \\
\hline $\mathrm{R}$ & $\begin{array}{l}\text { Normal } \\
\text { MDD }\end{array}$ & $\begin{array}{l}30 \\
30\end{array}$ & $\begin{array}{l}8.800 \\
12.533\end{array}$ & $\begin{array}{l}2.188 \\
3.683\end{array}$ & -4.773 & .000 \\
\hline IN & $\begin{array}{l}\text { Normal } \\
\text { MDD }\end{array}$ & $\begin{array}{l}30 \\
30\end{array}$ & $\begin{array}{l}15.533 \\
27.767\end{array}$ & $\begin{array}{l}4.006 \\
4.869\end{array}$ & -10.627 & .000 \\
\hline OUT & $\begin{array}{l}\text { Normal } \\
\text { MDD }\end{array}$ & $\begin{array}{l}30 \\
30\end{array}$ & $\begin{array}{l}16.567 \\
15.833\end{array}$ & $\begin{array}{l}4.739 \\
5.682\end{array}$ & .543 & .589 \\
\hline Control & $\begin{array}{l}\text { Normal } \\
\text { MDD }\end{array}$ & $\begin{array}{l}30 \\
30\end{array}$ & $\begin{array}{l}21.100 \\
20.367\end{array}$ & $\begin{array}{l}6.205 \\
5.732\end{array}$ & .475 & .636 \\
\hline Ex & $\begin{array}{l}\text { Normal } \\
\text { MDD }\end{array}$ & $\begin{array}{l}30 \\
30\end{array}$ & $\begin{array}{l}27.000 \\
38.567\end{array}$ & $\begin{array}{l}8.107 \\
11.461\end{array}$ & -4.513 & .000 \\
\hline DA & $\begin{array}{l}\text { Normal } \\
\text { MDD }\end{array}$ & $\begin{array}{l}30 \\
30\end{array}$ & $\begin{array}{l}116.833 \\
213.267\end{array}$ & $\begin{array}{l}27.759 \\
24.690\end{array}$ & -14.218 & .000 \\
\hline Neuroticism & $\begin{array}{l}\text { Normal } \\
\text { MDD }\end{array}$ & $\begin{array}{l}30 \\
30\end{array}$ & $\begin{array}{l}21.167 \\
41.067\end{array}$ & $\begin{array}{l}7.424 \\
5.369\end{array}$ & -11.897 & .000 \\
\hline
\end{tabular}

\section{Correlation and regression analyses:}

In the zero order correlation the clinical group showed a significant positive association between Internalized Anger and DA scores $(r=0.521, p<0.003)$, and DA scores and neuroticism $(r$ $=0.380, p<0.38$ ). DA scores and Neuroticism both were also seen to be positively correlated 
with Trait Anger, and Anger expression scores. While DA scores were found to be positively correlated with Anger Temperament, Neuroticism was positively associated with Anger reaction; DAS scores and Neuroticism scores were not correlated with Externalized Anger and Anger control scores. In partial correlation where Neuroticism was controlled DAS scores was seen to be positively correlated with Temperamental Anger and Internalized Anger.

In the control group, a significant positive association was observed between Internalized Anger and both DA scores $(r=0.511, p<0.004)$ and Neuroticism $(r=0.607, p<0.000)$, and DA scores and neuroticism $(r=0.415, p<0.022)$. DA scores and neuroticism were found to be negatively associated with Externalized Anger. No significant correlation was observed between DA scores and trait Anger, Anger control and Anger expression. Neuroticism failed to show any further significant correlations with Anger control, expression and trait Anger.

The results are tabulated in table II and table III.

Table II. Correlation between STAXI scores and other variables among MDD population

\begin{tabular}{|c|c|c|c|c|c|c|c|c|c|c|}
\hline $\begin{array}{l}\text { Correlatio } \\
\mathrm{n}\end{array}$ & $\begin{array}{l}\text { Controlle } \\
\text { d } \\
\text { Variables }\end{array}$ & Variables & Trait & $\mathrm{T}$ & $\mathrm{R}$ & IN & OUT & $\begin{array}{c}\text { CONTRO } \\
\mathrm{L}\end{array}$ & Ex & DA \\
\hline \multirow[t]{2}{*}{$\begin{array}{l}\text { Zero } \\
\text { order }\end{array}$} & None & DA & $\begin{array}{c}.471^{*} \\
*\end{array}$ & $\begin{array}{c}.519^{*} \\
*\end{array}$ & - & $\begin{array}{c}.521^{*} \\
*\end{array}$ & - & - & $.390^{*}$ & - \\
\hline & & $\begin{array}{c}\text { Neuroticis } \\
\mathrm{m}\end{array}$ & $\begin{array}{c}.484^{*} \\
*\end{array}$ & $\begin{array}{l}.459 * \\
*\end{array}$ & - & - & $\begin{array}{c}.385^{*} \\
*\end{array}$ & - & $\begin{array}{c}.516^{*} \\
*\end{array}$ & $\begin{array}{c}.380^{*} \\
*\end{array}$ \\
\hline Partial & $\begin{array}{c}\text { Neuroticis } \\
\mathrm{m}\end{array}$ & DA & - & $\begin{array}{l}.420 * \\
*\end{array}$ & - & $\begin{array}{c}.465^{*} \\
*\end{array}$ & - & - & - & - \\
\hline
\end{tabular}

*. Correlation is significant at the 0.05 level (2-tailed).

**. Correlation is significant at the 0.01 level (2-tailed). 
Table III. Correlation between STAXI scores and other variables among Normal population

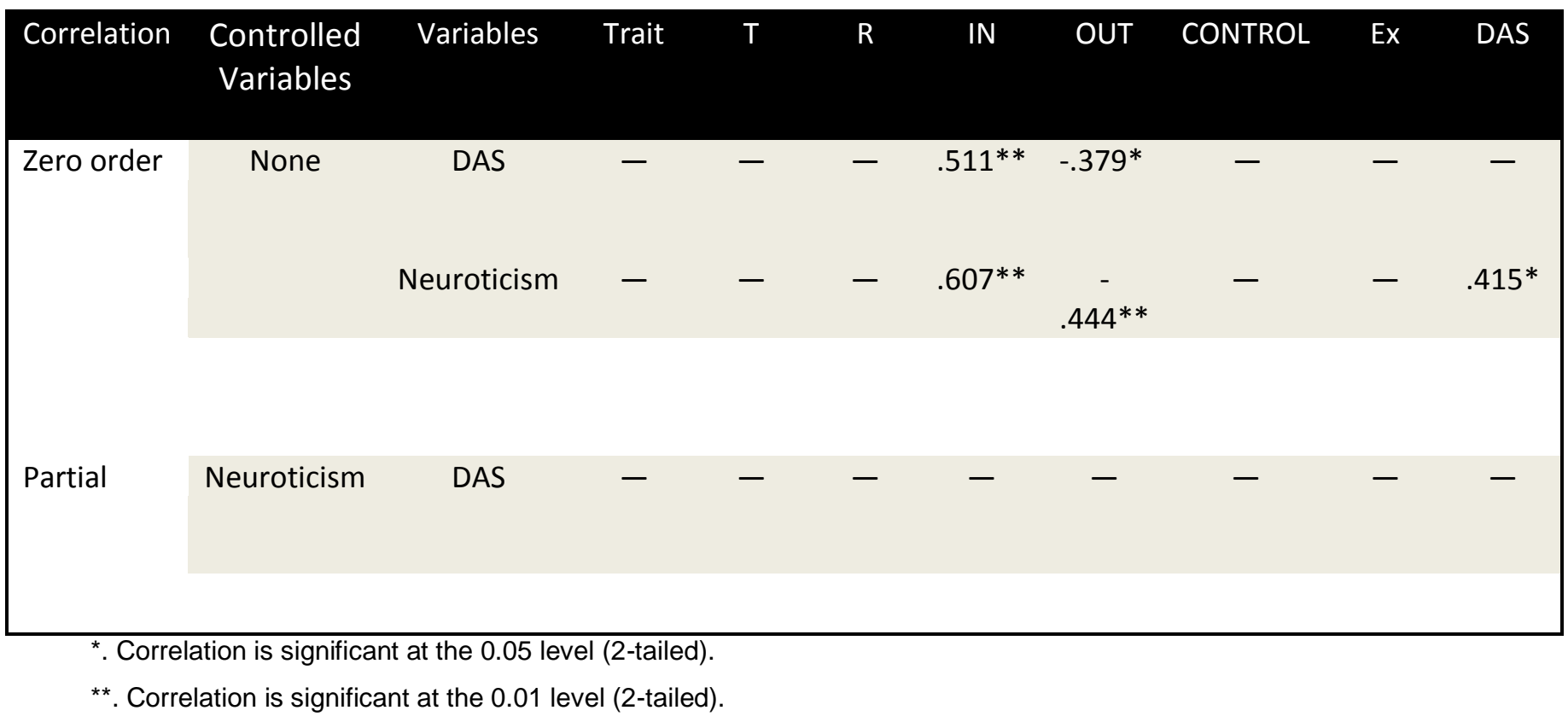

A Multiple regression analysis was conducted on each of the group using the stepwise entry method; DA scores and Neuroticism were taken as predictor variables with Internalized Anger as the Dependent Variable. In the clinical group a significant regression equation was calculated with DA scores acting as a predictor. It was seen that DA scores predicted $13.1 \%$ of Internalized Anger. In the control group only Neuroticism was retained in the significant regression equation and was found to be predicting $34.6 \%$ of Internalized Anger. The results are tabulated in table IV.

Table IV. Results of Multiple Regression for prediction of internalized anger in both the groups

\begin{tabular}{|llccccccc|}
\hline Models & Group & Predictors & Beta & R & $\begin{array}{c}\text { Adjusted } \\
\text { R Square }\end{array}$ & T & $\begin{array}{c}\text { SE of } \\
\text { estimate }\end{array}$ & $\begin{array}{c}\text { Sig. F } \\
\text { Change }\end{array}$ \\
\hline 1 & Normal & N & .607 & .607 & .346 & 4.039 & 3.241 & .000 \\
1 & MDD & DA & .521 & .521 & .245 & 3.230 & 4.229 & .003 \\
\hline
\end{tabular}




\section{Effect of Dysfunctional Attitudes on Orientation of Anger in Major Depressive Disorder patients}

\section{DISCUSSION}

The goal of the present study was to understand the direction of Anger among MDD population in India and also to investigate the relation between Dysfunctional Attitude and direction of Anger. Several studies have established a relation between Depression and Anger suggesting that depression primes angry feelings, hostile ideas and even aggressive behaviors (Shin H, 2010). The findings of the present study supports the previous findings, high trait Anger and Anger expression scores were observed in the clinical group. However the high Anger scores were mainly contributed by Internalized Anger scores, as the Externalized Anger and Anger control scores were seen to be lower than the normal group. In this study the Internalized Anger scores for the clinical group were seen to be much higher than the normal group, a finding that is consistent with studies reporting of a positive association between Anger suppression and depressive symptoms (Bridewell \& Chang, 1997; Kopper \& Epperson, 1996; Cheung et al, 2010). The high Internalized Anger and trait Anger along with Dysfunctional Attitude scores among the MDD population suggests a relation between the two variables.

In order to understand the role played exclusively by Dysfunctional Attitude on the direction of Anger, a Zero order, a Partial Correlation (holding Neuroticism constant) and a multiple regression was conducted on each group.

As expected, results of partial correlation showed a positive association among Dysfunctional Attitude, Internalized Anger and Temperamental Anger in MDD group when N was controlled. In zero order correlation within the group, Dysfunctional Attitude was found to be correlated with Trait as well as Internalized Anger, implying the effect of $\mathrm{N}$ on trait Anger but not on Internalized Anger. Dysfunctional Attitude has long been associated with Depressive symptoms, cognitive vulnerability hampers rational understanding of the problems by increasing the propensity of an individual to construe information distortedly and negatively which may also lead to the experience of Anger. Furthermore when Neuroticism was constant Dysfunctional Attitude seized to be correlated with trait Anger, but was positively associated with Temperamental Anger, a subscale of Trait Anger that measures the proclivity to experience and express Anger without provocation. A finding that suggests the effect of covariate Neuroticism contributing towards Trait Anger along with Dysfunctional Attitude, and the sole effect of Dysfunctional Attitude on the propensity towards the feelings of Anger.

However in the Normal group partial correlation yielded no significant correlation between Anger and Dysfunctional Attitude, hence suggesting the link shared by Dysfunctional Attitude and Anger to be valid only within the Clinical group. In the control group zero order correlation it was also seen that Dysfunctional Attitude and Neuroticism was negatively associated with Externalized Anger and Neuroticism was positively associated with Internalized Anger, a finding that needs further research with larger sample size for a definite conclusion.

To investigate this relationship further a Multiple Regression was conducted between the 3 variables on each group. Dysfunctional Attitude was found to be acting as a predictor for Internalized Anger only in the MDD group and Neuroticism was seen to be acting as a predictor variable for Internalized Anger only in the control group. Hence, the results of the present study 
imply a definite link between Dysfunctional Attitude and Anger suppression in depressed patients but this relationship does not hold true for the control group. This might be due to the fact that Dysfunctional Attitude induces unreasonable believes which in turn influences Internalized Anger, the control group population devoid of this cognitive distortion as a result shares much less Internalized Anger scores which are solely influenced by Neuroticism.

Thus in our study we see that although Anger scores are influenced by Neuroticism among normal population, the influence on orientation of Anger among depressive population is being predominated by the Cognitive distortions, and the role of Neuroticism mainly lies in influencing the trait Anger scores within the clinical group.

The limitation of this study was partially owing to the low sample size and partly due to the cross sectional nature of the study, a longitudinal follow up study should be done focusing the relationship between Dysfunctional Attitude and Anger orientation. Future studies should focus on longitudinal study designs with a larger sample size and treatment based experimental studies. Some of the studies on CBT have shown an improvement of Dysfunctional Attitude scores after treatment, hence studies may also incorporate a measurement of Anger that assess the Internalized Anger before and after treatment of MDD. Furthermore researches should be conducted in different cultures to assess the generalizability of these results.

However, despite the limitations, the present study is the first to assess the association between Dysfunctional Attitude and orientation of Anger in an Indian clinical population; it also extends the findings of previous studies that have associated Dysfunctional Attitude and Anger with depression by showing that Dysfunctional Attitude may be responsible for the direction of Anger characterizing the MDD population in India.

\section{CONCLUSION}

The result of the present study indicates a definite role played by Dysfunctional Attitude in the direction of Anger among the MDD population of India and also elucidates the role of the covariate Neuroticism in the orientation of Anger. These findings have diagnostics as well as therapeutic implications which may help in curbing the suicidal rate among the MDD population caused by high Internalized Anger. It is also encouraging for theoretical frameworks that assume that Dysfunctional beliefs are partially responsible for normal human suffering (Ellis, 2001; Hayes et al., 1999).

\section{REFERENCES}

1. Akiskal, H. S., Hirschfeld, R., \& Yerevanian, B. I. (1983). The relationship of personality to affective disorders: a critical review. Archives of General Psychiatry, 40(7), 801.

2. Barnett, P. A., \& Gotlib, I. H. (1988). Psychosocial functioning and depression: distinguishing among antecedents, concomitants, and consequences. Psychological bulletin, 104(1), 97. 
3. Becker EW, Lesiak WJ ( 1977) Feelings of hostility and personal control as related to depression. Journal of Clinical Psychology ; 33: 654-7.

4. Bridewell, W. B., \& Chang, E. C. (1997). Distinguishing between anxiety, depression, and hostility: Relations to Anger-in, Anger-out, and Anger control. Personality and Individual Differences, 22(4), 587-590.

5. Brody CD, Haaga DAF, Kirk L, et al (1999) Experiences of Anger in people who have recovered from depression and never-depressed people. Journal of Nervous and Mental Disease; 187: 400-5.

6. Busch, F. N. (2009). Anger and depression. Advances in Psychiatric Treatment, 15(4), 271-278.

7. Cheung, R. Y., \& Park, I. J. (2010). Anger suppression, interdependent self-construal, and depression among Asian American and European American college students. Cultural diversity \& ethnic minority psychology, 16(4), 517.

8. Costa, P. T., Jr., \& McCrae, R. R. (1992). NEO PI-R professional manual. Odessa, FL: Psychological Assessment Resources, Inc.

9. Doucette-Gates, A., Firestone, R. W., \& Firestone, L. A. (1999). Assessing violent thoughts: The relationship between thought processes and violent behavior. Psychologica belgica, 39(2-3), 113-134.

10. Ebrahimi A, Afshar H, Doost HTN, Mousavi SGh, Moolavi H Attitude scale and general health questionnaire subscales predict depression? J Res Med Sci 2012; 17(1): 40-44

11. Ellis, A. (2001). Overcoming destructive beliefs, feelings, and behaviors: New directions for rational emotive behavior therapy. Amherst, NY, US: Prometheus Books, $421 \mathrm{pp}$.

12. Goldberg, D. P., \& Hillier, V. F. (1979). A scaled version of the General Health Questionnaire. Psychological medicine, 9(01), 139-145.

13. Goldman L, Haaga DAF (1995) Depression and the experience and expression of Anger in marital and other relationships. Journal of Nervous and Mental Disease; 183: 505-9. Medline

14. Hayes, S. C., Strosahl, K. D., \& Wilson, K. G. (1999). Acceptance and commitment therapy: An experiential approach to behavior change. The Guilford Press: New York, NY, US, 304 pp.

15. Koh KB, Kim CH, Park JK (2002) Predominance of Anger in depressive disorders compared with anxiety disorders and somatoform disorders. Journal of Clinical Psychiatry; 63: 486-92.

16. Kopper BA, Epperson DL. The experience and expression of Anger: Relationships with gender, gender role socialization, depression, and mental health functioning. Journal of Counseling Psychology. 1996; 43(2):158-165.

17. Lomax, C. L. and Lam, D. (2011), Investigation into activation of Dysfunctional schemas in euthymic bipolar disorder following positive mood induction. British Journal of Clinical Psychology, 50: 115-126.

18. Martin, R., Watson, D., \& Wan, C. K. (2000). A Three-Factor Model of Trait Anger: Dimensions of Affect, Behavior, and Cognition. Journal of Personality, 68(5), 869-897.

19. Nesbit, S. M., \& Conger, J. C. (2012). Predicting aggressive driving behavior from Anger and negative cognitions. Transportation research part F: traffic psychology and behaviour, 15(6), 710-718.

20. Oliver, J. M., \& Baumgart, E. P. (1985). The Dysfunctional Attitude Scale: Psychometric properties and relation to depression in an unselected adult population. Cognitive therapy and research, 9(2), 161-167. 
21. Rowland, A. V. (2012). A correlational study of state and trait Anger in relation to the five-factor model of personality (Doctoral dissertation).

22. Sharpe, J. P., \& Desai, S. (2001). The revised Neo Personality Inventory and the MMPI-2 Psychopathology Five in the prediction of aggression. Personality and Individual Differences, 31(4), 505-518.

23. Shin, H. (2010). Does depression moderate or mediate the relations between deficits in competence and aggression? A short-term longitudinal study of Korean children. School Psychology International, 31(4), 331-352.

24. Spielberger, C.D., 1991. State-Trait Anger Expression Inventory (STAXI). Revised Research Edition Psychological Assessment and Resources, Inc., Florida.

25. Swanson JW, Holzer CE, Ganju VK, et al (1990) Violence and psychiatric disorder in the community: evidence from the Epidemiologic Catchment Area surveys. Hospital and Community Psychiatry; 41: 61-70.

26. Thomas, J. and Altareb, B. (2012), Cognitive vulnerability to depression: An exploration of Dysfunctional Attitudes and ruminative response styles in the United Arab Emirates. Psychology and Psychotherapy: Theo, Res, Pra, 85: 117-121

27. Weissman, A. (1979). Dysfunctional Attitude Scale (DAS). Acceptance and Commitment Therapy. Measures Package, 54.

28. Widiger, T. A., \& Trull, T. J. (1992). Personality and Psychopathology: An Application of the Five-Factor Model. Journal of personality, 60(2), 363-393.

29. Wolfersdorf M, Kiefer A (1998) Depression and aggression. A control group study on the aggression hypothesis in depressive disorders based on the Buss Durkee Questionnaire. Psychiatrische Praxis; 25: 240-5. 